\title{
Medroxyprogesterone acetate (Depo-Provera) and bone mineral density loss
}

Reason for posting: Medroxyprogesterone acetate is an injectable agent widely used for contraception and the treatment of endometriosis. However, a warning was recently issued that patients taking this drug may experience a significant loss of bone mineral density. ${ }^{1}$

The drug: Medroxyprogesterone acetate is injected intramuscularly in a standard dose $(150 \mathrm{mg})$ once every 3 months. It confers its reversible contraceptive effect by inhibiting gonadotropin secretion, preventing follicle $\infty$ maturation and ovulation, and c causing endometrial thinning. Disrupted menses (bleeding, amenorrhea or both), fluid retention, weight changes, dizziness, headache, weakness and fatigue are frequently experienced by women taking the drug.

\section{Canadian Adverse} Reaction Newsletter

\section{Bulletin canadien des effets indésirables}

To receive the Newsletter and health product Advisories by email, join Health Canada's Health_Prod_Info mailing list.

Go to www.hc-sc.gc.calhpfb-dgpsa Itpd-dpt/subscribe_e.html.

Inscrivez-vous à la liste Info_Prod_Santé de Santé Canada pour recevoir par courriel le Bulletin et les Avis au sujet des produits de santé. Rendez-vous à l'adresse www.hc-sc.gc.calhpfb-dgpsaltpd-dpt Isubscribe f.html.

Report adverse reactions toll free to Health Canada • Signaler sans frais des effets indésirables à Santé Canada

Tel./Tél. : 866 234-2345

Fax/Téléc. : 866 678-6789

Email/Courriel: cadrmp@hc-sc.gc.ca

Health Santé Canada Canada Canadà
Other rare but serious adverse effects include mood changes, thromboembolic diseases, ocular disorders (including vision loss, proptosis, diplopia or migraine) and reduced glucose tolerance. About 3 in 1000 women taking the drug will experience an accidental pregnancy in the first year of continuous use. It is contraindicated in pregnant women, women who have undiagnosed vaginal bleeding, malignant breast disease, active thrombophlebitis, past thromboembolic disorders or cerebral vascular disease, and in women with significant liver disease.

Medroxyprogesterone acetate decreases serum estrogen levels, which can lead to bone mineral density loss. In an unpublished study involving women above the age of 18 who used the drug for up to 5 years, bone mineral density in the spine and hip was reduced by $5 \%$ to $6 \%$ below baseline. ${ }^{2}$ In contrast, women in the control group, who were not using hormonal contraception, had no significant change in bone mineral density. Loss of density was greatest in the first 2 years of use. Two years after stopping the drug, bone mineral density was only partially recovered. Preliminary results from an ongoing open-label self-selected nonrandomized group of adolescent women aged 12-18 years showed a similar decrease in bone mineral density of $4 \%-6.9 \%$ after 4.6 years of study. ${ }^{2}$ This decline was not seen in a group of unmatched adolescents not receiving the drug. It is unknown whether use of medroxyprogesterone acetate will lead to osteoporotic fractures later in life.

What to do: This drug, which is widely taken by patients for whom compliance is an issue (e.g., adolescents and young adults), may cause a loss of bone density that may not be fully reversible in a group that is least able to afford such a loss. A patient's risk factors for osteoporosis (a family history of osteoporosis; long-term use of glucocorticoids, heparin or anticonvulsant therapy; malabsorption states; hyperparathyroidism; hyperthyroidism; smoking; low dietary calcium intake; excessive caffeine or alcohol intake; weight $<57 \mathrm{~kg}$; anorexia or bulemia) ${ }^{2,3}$ should be part of the risk-benefit analysis of prescribing the drug. Only if other methods of birth control are inappropriate should the drug be used as a contraceptive for the long term ( $>2$ years). Women who take the drug for more than 2 years should have their bone mineral density monitored. When interpreting bone mineral density test results in adolescents, the patient's age and degree of skeletal maturation should be taken into account. Studies are lacking on how best to prevent and treat medroxyprogesterone acetate-associated bone mineral density loss; however, it may be wise to routinely recommend regular weightbearing exercise, smoking cessation, and calcium and vitamin $\mathrm{D}$ supplementation to women prescribed the drug.

\section{Eric Wooltorton}

Associate Editor, CMAJ

\section{References}

1. Health Canada endorsed important safety information on Depo-Provera (medroxyprogesterone acetate) [letter]. Nov. 22, 2004. Available: www.hc-sc .gc.ca/hpfb-dgpsa/tpd-dpt/depo-provera hpc_e.html (accessed 2005 Feb 8).

2. Depo-Provera (medroxyprogesterone acetate injectable suspension) revised product monograph, Pfizer. Available: www.fda.gov/medwatch/SAFETY/20 04/safety04.htm\#Depo [click on: November, 2004 - Label - Pfizer] (accessed 2005 Feb 8)

3. Brown JP, Josse RG, for the Scientific Advisory Council of the Osteoporosis Society of Canada. 2002 clinical practice guidelines for the diagnosis and management of osteoporosis in Canada. CMA7 2002;167(10 Suppl):S1-34. 